\title{
Environmental Contamination with Vancomycin-Resistant Enterococci from Hospital Sewage in Portugal
}

\author{
Carla Novais, ${ }^{1}$ Teresa M. Coque, ${ }^{2}$ Helena Ferreira, ${ }^{1}$ João Carlos Sousa, ${ }^{3}$ and Luisa Peixe ${ }^{1 *}$ \\ REQUIMTE Laboratório de Microbiologia, Faculdade de Farmácia, Universidade do Porto, Porto, Portugal ${ }^{1}$; \\ Servicio de Microbiología, Hospital Universitario Ramón y Cajal, Madrid, Spain ${ }^{2}$; and Microbiologia, \\ Faculdade Ciências da Saúde, Universidade Fernando Pessoa, Porto, Portugal ${ }^{3}$
}

Received 27 September 2004/Accepted 20 December 2004

\begin{abstract}
Vancomycin-resistant enterococci (VRE) were detected in samples of sewage obtained downstream of hospitals of the Porto area in Portugal, and in samples from the Douro Estuary. Clonal analysis, Tn1546 typing, and presence of putative virulence traits indicate the clinical origin of these isolates. This observation highlights the importance of hospital sewage in the VRE contamination of the environment.
\end{abstract}

Enterococci have been traditionally considered as indicators of fecal contamination of drinking and recreational waters (1), although they are usually recovered at high concentrations from natural environments lacking exposure to heavy fecal contamination, such as rivers, seawater, and nonagricultural soils $(2,11)$. Release of antibiotic-resistant bacteria to the community is therefore of particular concern since they might proliferate in soil and surface waters, persist and spread in different environments $(11,14,15,25,26)$, and transfer antibiotic resistance genes among different species $(3,12)$. The enterococcal population in wastewater from different European countries and the United States has been previously evaluated $(4,11,12)$, but knowledge of the relationship between enterococcal populations from sewage or surface waters and those recovered from hospitalized patients is scarce (11).

Vancomycin-resistant enterococci (VRE) are one of the most worrisome pathogens in hospitals in the United States, and they are starting to increase in European health institutions, Portugal being the area with the currently highest VRE prevalence (Annual Report of European Antibiotic Resistance Surveillance System, 2002 [http//:www.earss.rivm]). We screened hospital sewage and river water samples for the presence of antibiotic-resistant enterococci, characterizing clonal relatedness and genes coding for antibiotic resistance and putative virulence traits.

Twenty-six sewage samples (SW) were collected in an urban sewer from January 2001 to May 2002 in an area near four Porto hospitals. Twelve samples were collected from sewage upstream of the hospitals (SWU), flowing from residential neighborhoods. Fourteen samples were collected from sewage downstream of health institutions (SWD). Porto wastewaters are drained to the Douro river estuary. Samples were obtained from the shore of this estuary $(n=3)$ and from the Coura and Sousa Rivers $(n=2)$, tributaries of the Douro before the estuary.

Samples were collected in sterile bottles and kept at $4^{\circ} \mathrm{C}$ until processing ( 2 to $8 \mathrm{~h}$ ). Slanetz-Bartley agar plates with and

\footnotetext{
* Corresponding author. Mailing address: Laboratório de Microbiologia, Faculdade de Farmácia, Universidade do Porto, Rua Aníbal Cunha, 4050 Porto, Portugal. Phone: 351-2-22078946. Fax: 351-222003977. E-mail: lpeixe@ff.up.pt.
}

without vancomycin $(6 \mathrm{mg} / \mathrm{liter})$ were used to incubate membranes with filtered aliquots $(0.45$-mm-pore-size membranes; Millipore Corporation) of $100-\mathrm{ml}$ river samples and $0.1-\mathrm{ml}$ aliquots of SWU and SWD that were directly spread on plates. Susceptibility testing was performed following CLSI (formerly NCCLS) guidelines and using the recommended breakpoints to define resistance (18). A multiplex PCR assay was used for species identification and vancomycin resistance gene detection (8). VRE isolates were typed by pulsed-field gel electrophoresis (PFGE) $(16,21)$. Genes coding for resistance to aminoglycosides, streptogramins, and macrolides, the backbone structure of the Tn1546 harbored by VRE isolates, and the presence of some putative enterococcal virulence factors (cytolysin [Cyl], gelatinase [Gel], aggregation substance [Agg], hyaluronidase [Hyl], and enterococcal surface protein [Esp]) were investigated as described previously (10, 17, 20, 23, 24, 27). Conjugation experiments were performed using Enterococcus faecalis strain JH2-2 or E. faecium GE1 as recipients (19). Amplification and sequencing of the purK allele from vancomycin-resistant Enterococcus faecium clones were performed as previously reported (13). Statistical significance for comparison proportions was calculated by the chi-square test ( $P<0.05$ was considered to be statistically significant).

Enterococci were isolated in 25 out of $26(96 \%)$ of the sewage samples and 5 out of $5(100 \%)$ of the river samples. VRE were isolated from 11/14 (79\%) samples collected from SWD and in 2/3 samples from the Douro Estuary, being better recovered from plates containing vancomycin (21/31 isolates; $68 \%$ ) than from those supplemented with ampicillin (6/31; $19 \%)$ or gentamicin $(3 / 31 ; 10 \%)$ or from Slanetz plates without antibiotic $(1 / 31 ; 3 \%)$. VRE were not detected in SWU or in the rivers before the Douro Estuary. Rates of resistance to ampicillin, ciprofloxacin, and erythromycin and of high-level resistance (HLR) to streptomycin, gentamicin, or kanamycin were higher among isolates from SWD samples than among those from SWU samples. Similar rates of resistance to tetracycline and chloramphenicol were found among SWU and SWD (Table 1).

$\operatorname{van} \mathrm{A}, \operatorname{van} \mathrm{B}$, and $\operatorname{van} \mathrm{C} 1$ genes were detected in 27,4 , and 1 VRE isolates, respectively. Among these strains, HLR to gentamicin and erythromycin was always due to $\operatorname{aac}\left(6^{\prime}\right)$-aph $\left(2^{\prime \prime}\right)$, and $\operatorname{erm}(\mathrm{B})$. Transference of $\operatorname{van} \mathrm{A}$ was achieved for $13 / 24$ 
TABLE 1. MIC distribution and percentage of resistance to different antibiotics tested in enterococci isolated from Portuguese sewage and rivers

\begin{tabular}{|c|c|c|c|c|c|c|c|c|c|c|c|c|}
\hline \multirow{2}{*}{ Antimicrobial agent ${ }^{a}$} & \multirow{2}{*}{ Origin $(n)^{b}$} & \multicolumn{10}{|c|}{ No. of isolates at indicated MIC (mg/liter) } & \multirow{2}{*}{$\%$ Resistance } \\
\hline & & & & & $\leq 4$ & 8 & 16 & 32 & 64 & 128 & $\geq 256$ & \\
\hline \multirow[t]{3}{*}{ Vancomycin** } & SWU (37) & & & & 36 & & 1 & & & & & 0 \\
\hline & SWD (93) & & & & 67 & 1 & & & & 4 & 21 & 27 \\
\hline & $\mathrm{R}(18)$ & & & & 12 & & & & & & 6 & 33 \\
\hline \multirow{4}{*}{ Teicoplanin** } & & & & & $\leq 4$ & 8 & 16 & 32 & 64 & 128 & $\geq 256$ & \\
\hline & SWU (37) & & & & 37 & & & & & & & 0 \\
\hline & SWD (93) & & & & 72 & & 1 & 2 & & & 18 & 22 \\
\hline & $\mathrm{R}(18)$ & & & & 11 & & & 2 & 4 & 1 & & 39 \\
\hline \multirow{4}{*}{ Ampicillin* } & & & & & $\leq 4$ & 8 & 16 & $\geq 32$ & & & & \\
\hline & SWU (37) & & & & 33 & & & 4 & & & & 11 \\
\hline & SWD (93) & & & & 51 & & & 42 & & & & 45 \\
\hline & $\mathrm{R}(18)$ & & & & 12 & & & 6 & & & & 33 \\
\hline \multirow{4}{*}{ Tetracycline } & & & & & $\leq 4$ & 8 & 16 & 32 & $\geq 64$ & & & \\
\hline & SWU (37) & & & & 18 & 4 & 2 & 5 & 8 & & & 41 \\
\hline & SWD (93) & & & & 51 & 8 & 13 & 12 & 9 & & & 37 \\
\hline & R (18) & & & & 16 & & 1 & 2 & & & & 17 \\
\hline \multirow{4}{*}{ Erythromycin } & & $\leq 0.5$ & 1 & 2 & 4 & 8 & 16 & $\geq 32$ & & & & \\
\hline & SWU (37) & 9 & 1 & 3 & 2 & 4 & & 18 & & & & 59 \\
\hline & SWD (93) & 10 & 3 & 7 & 9 & & & 64 & & & & 69 \\
\hline & $\mathrm{R}(18)$ & 3 & 3 & 2 & 3 & & 1 & 6 & & & & 39 \\
\hline \multirow{4}{*}{ Ciprofloxacin** } & & $\leq 0.5$ & 1 & 2 & 4 & 8 & $\geq 16$ & & & & & \\
\hline & SWU (37) & 5 & 13 & 9 & 5 & 2 & 3 & & & & & 27 \\
\hline & SWD (93) & 5 & 8 & 10 & 12 & 8 & 50 & & & & & 75 \\
\hline & $\mathrm{R}(18)$ & & 3 & 6 & 2 & 1 & 6 & & & & & 56 \\
\hline \multirow{4}{*}{ Chloramphenicol } & & & & & $\leq 4$ & 8 & 16 & 32 & $\geq 64$ & & & \\
\hline & SWU (37) & & & & 9 & 18 & 6 & 2 & 2 & & & 11 \\
\hline & SWD (93) & & & & 18 & 44 & 15 & 14 & 2 & & & 17 \\
\hline & R (18) & & & & 2 & 12 & 4 & & & & & 0 \\
\hline \multirow{4}{*}{ Nitrofurantoin } & & & & $\leq 2$ & 4 & 8 & 16 & 32 & 64 & 128 & $\geq 256$ & \\
\hline & SWU (37) & & & & & 1 & 9 & 3 & 19 & 5 & & 14 \\
\hline & SWD (93) & & & 1 & 4 & 22 & & 15 & 45 & 6 & & 6 \\
\hline & R (18) & & & & 1 & 1 & & 7 & 2 & 7 & & 39 \\
\hline \multirow{4}{*}{ Linezolid } & & & $\leq 1$ & 2 & 4 & $\geq 8$ & & & & & & \\
\hline & SWU (37) & & 9 & 9 & 19 & & & & & & & 0 \\
\hline & SWD (93) & & 11 & 35 & 47 & & & & & & & 0 \\
\hline & $\mathrm{R}(18)$ & & & 6 & 12 & & & & & & & 0 \\
\hline \multirow{4}{*}{ Gentamicin } & & & $\leq 256$ & & $\geq 500$ & & & & & & & \\
\hline & SWU (37) & & 26 & & 11 & & & & & & & 30 \\
\hline & SWD (93) & & 56 & & 37 & & & & & & & 40 \\
\hline & $\mathrm{R}(18)$ & & 15 & & 3 & & & & & & & 17 \\
\hline \multirow{4}{*}{ Streptomycin } & & & $\leq 256$ & & 500 & & 1,000 & & $\geq 2,000$ & & & \\
\hline & SWU (37) & & 22 & & & & 3 & & 12 & & & 32 \\
\hline & SWD (93) & & 41 & & & & 7 & & 45 & & & 48 \\
\hline & R (18) & & 17 & & & & & & 1 & & & 6 \\
\hline \multirow{4}{*}{ Kanamycin } & & & $\leq 256$ & & $\leq 500$ & & 1,000 & & $\geq 2,000$ & & & \\
\hline & SWU (37) & & 22 & & 13 & & 6 & & 18 & & & 49 \\
\hline & SWD (93) & & 41 & & 24 & & 12 & & 57 & & & 61 \\
\hline & $\mathrm{R}(18)$ & & 17 & & 14 & & & & 4 & & & 22 \\
\hline
\end{tabular}

${ }^{a}$ Differences in the susceptibility to ampicillin, vancomycin, teicoplanin, and ciprofloxacin among isolates recovered from sewage samples were statistically significant $(*, P<0.05 ; * *, P<0.005)$.

${ }^{b}$ SWU, sewage upstream; SWD, sewage downstream; R, river.

(54\%) isolates. vanA and erm(B) were observed in 8/14 (57\%) cases, and cotransference of vanA and aph(3')-IIIa in 13/14 $(93 \%)$ cases. Four transconjugants harbored vanA, erm $(\mathrm{B})$, and $\operatorname{aph}\left(3^{\prime}\right)$-IIIa (29\%) (Table 2).
Nine PFGE types (8 E. faecium and 1 E. faecalis) were identified among VRE from sewage, and two E. faecium PFGE types were found among VRE from the Douro Estuary (Table 2). Clones B, C, and L were observed on at least two 


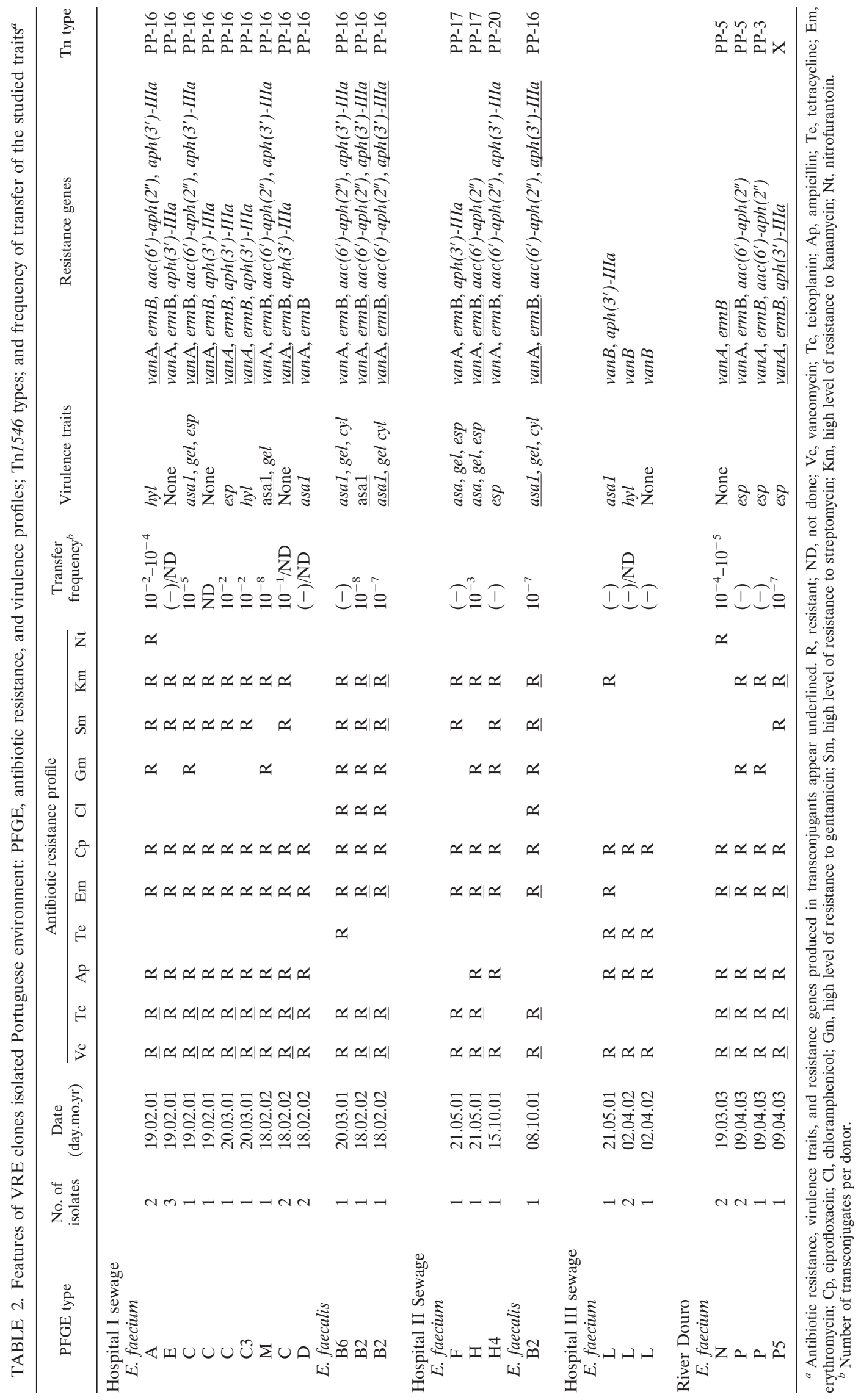


TABLE 3. Tn1546 types found among VRE clinical isolates recovered in environmental samples ${ }^{a}$

\begin{tabular}{lcccccccccc}
\hline Type $^{a}$ & $\begin{array}{c}\mathrm{p} 1 \mathrm{p} 2 \\
(22-1330)\end{array}$ & $\begin{array}{c}\mathrm{p} 3 \mathrm{p} 4 \\
(1222-2353)\end{array}$ & $\begin{array}{c}\mathrm{p} 5 \mathrm{p} 6 \\
(2227-3525)\end{array}$ & $\begin{array}{c}\mathrm{p} 7 \mathrm{p} 8 \\
(2769-4042)\end{array}$ & $\begin{array}{c}\mathrm{p} 9 \mathrm{p} 10 \\
(3569-4793)\end{array}$ & $\begin{array}{c}\mathrm{p} 11 \mathrm{p} 12 \\
(4675-6353)\end{array}$ & $\begin{array}{c}\mathrm{p} 13 \mathrm{p} 14 \\
(6229-8021)\end{array}$ & $\begin{array}{c}\mathrm{p} 15 \mathrm{p} 16 \\
(6979-8920)\end{array}$ & $\begin{array}{c}\mathrm{p} 17 \mathrm{p} 18 \\
(8889-10473)\end{array}$ & $\begin{array}{c}\mathrm{p} 19 \mathrm{p} 1 \\
(10403-10830)\end{array}$ \\
\hline PP-3 & $(+)$ & $(+)$ & $(+)$ & $(+)$ & $(+)$ & $(+)$ & $(+)$ & $(+)$ & $(-/+)$ & $(-)$ \\
PP-5 & $(+)$ & $(+)$ & $(+)$ & $(+)$ & $(+)$ & $(-)$ & $(+)$ & $(+)$ & $(++)^{b}$ & $(-)$ \\
PP-16 & $(-)$ & $(-)$ & $(-)$ & $(-)$ & $(-)$ & $(+)$ & $(+)$ & $(+)$ & $(+)$ & $(+)$ \\
PP-17 & $(-)$ & $(-)$ & $(-)$ & $(-)$ & $(-)$ & $(+)$ & $(+)$ & $(-)$ & $(+)$ & $(+)$ \\
X & $(-)$ & $(-)$ & $(-)$ & $(-)$ & $(-)$ & $(+)$ & $(+)$ & $(-)$ & $(-)$ & $(+)$ \\
PP-20 & $(-)$ & $(-)$ & $(-)$ & $(-)$ & $(-)$ & $(-)$ & $(+)$ & $(-)$ & $(-)$ & $(+)$ \\
\hline
\end{tabular}

${ }^{a}$ Tn1546 types were designed according to Woodford scheme (11). For those that did not have a specific previously described type, we used our own designation (PP from Portugal-Oporto followed by a number randomly chosen). (+), amplification; $(-)$, no amplification; $(++)$, amplification of sequences larger than those of the expected size. For PP-3, amplification was negative for p17p18 but positive using ISEf1-F (5'-GGT GTT ACG ATG TCT GAA ATT GC-3') and p18.

${ }^{b}$ Amplification was positive using ISEf1-F and p18.

different occasions over 1 year, type B being recovered from sewage of hospitals I and II. Some of the PFGE types (B, C, D, $\mathrm{F}, \mathrm{N}$, and $\mathrm{P}$ ) were also observed in the hospital setting (data not shown). Six different variants of Tn1546 (PP3, PP5, PP-16, PP-17, PP-20, and X) were identified (Table 3 ). Four variants (PP-16, PP-17, PP-20, and X) lack amplicons with primers corresponding to regions associated with transposition functions, and five Tn1546 types (PP-3, PP5, PP-17, PP-20, and X) showed alterations in regions downstream of vanA. Tn1546 variants PP5 and PP3, found in E. faecium isolates from the Douro Estuary, contained an ISEf1 insertion, which has been described only among Tn1546 from clinical enterococcal isolates from Portugal (19). Most vancomycin-resistant E. faecium isolates $(n=22 / 31 ; 71 \%)$ contained at least one trait associated with virulence. Different combinations of putative virulence factors were detected: $\operatorname{esp}^{+}(n=6), h y l^{+}(n=5), a s a 1^{+}$ $(n=3), \mathrm{asal}^{+} \mathrm{gel}^{+}(n=1), \mathrm{asal}^{+} \mathrm{gel}^{+} \mathrm{cyl}^{+}(n=3)$, and $\mathrm{asal}^{+}$ $\mathrm{gel}^{+} \operatorname{esp}^{+}(n=3)$. Isolates within clonal types $\mathrm{B}, \mathrm{C}$, and $\mathrm{L}$ contained variable virulence patterns. The allele purK-1, associated with epidemic E. faecium clinical isolates (13), was detected in river and sewage clones.

Antibiotic resistance, virulence profiles, and the presence of the allele purK-1 in enterococcal isolates from SWD and river estuary, but not in those from SWU samples, suggest a nosocomial origin of these strains and thus a poor efficiency of wastewater management, which is often observed in European and American wastewater treatment plants $(7,11,12,25)$. The persistence of particular VRE PFGE types in wastewater for at least a 1-year period might reflect a better fitness of specific clones able to survive under harmful conditions or a continuous leaking of particular strains from health institutions, both able to contribute to the spread of hospital-specific enterococcal ecovars to the environment (13). The presence of $E$. faecalis clone $\mathrm{B}$ in hospitals of three different Portuguese cities for a 7-year period (19) suggests a wide dissemination of particular strains in the community which might be occasionally reintroduced in nosocomial institutions (14). In addition, the presence of antibiotic-resistant enterococci, including VRE, in the estuary area of the Douro River is indicative of fecal human contamination from both community and hospitals. Since this zone is used for bathing, recreation, and sport fishing and since enterococci can survive for long periods in the algal mat (26), shellfish $(11,28)$, and seagulls $(5)$, the risk of acquisition by humans of enterococcal genogroups of hospital origin from the environment cannot be discarded (14).

The variable antibiotic and virulence profiles among isolates of PFGE types B, L, and C suggest multiple horizontal gene transfer events in sewage or release of particular clones carrying different genetic elements available from local metagenomes $(3,19)$. A great heterogeneity of Tn1546 has been observed among enterococcal isolates from different ecological origins $(27,29)$, with some types being associated with specific hosts or settings $(19,27,29)$ while virulence traits are scarcely found outside the nosocomial environment $(6,9,10,13)$. On the other hand, differences in the transferability of specific Tn1546 among vancomycin-resistant E. faecium isolates belonging to the same clone suggest that different transfer mechanisms may play a role in the dissemination of VRE. The presence of mobile elements containing particular antibiotic resistance genes or virulence determinants in the community could trigger the dissemination of enterococcal isolates carrying elements coding resistance and/or virulence determinants (22) and enhance the risk to transmission to other environmental bacterial as already reported $(3,22)$.

Our data suggest that both particular clones and mobile elements carrying antibiotic resistance or virulence associated to the clinical setting might be continuously contaminating the community environment through wastewater. Reducing the release of bacteria or genetic elements from the clinical setting to the community is becoming a critical issue to avoid the buildup of environmental reservoirs of antibiotic resistance.

We are very grateful to Fernando Baquero for critical reading of the manuscript and to SMAS Porto, Divisão de Controlo de Qualidade and Departamento de Águas Residuais, for the collection of samples.

Carla Novais was supported by a fellowship from Fundação para a Ciência e Tecnologia (SFRH/BD/3372/2000), and the present work was partially supported by FSE/FEDER (POCTI/EFP/39885/2001).

\section{REFERENCES}

1. Anonymous. 1999. Standard methods for examination of water and wastewater, 20th ed., p. 1220. American Public Health Association and Water Environment Federation, Washington, D.C.

2. Ator, L. L., and M. J. Starzyk. 1976. Distribution of group D streptococci in rivers and streams. Microbios 16:91-104.

3. Baquero, F. 2004. From pieces to patterns: evolutionary engineering in bacterial pathogens. Nat. Rev. Microbiol. 2:510-518.

4. Blanch, A. R., J. L. Caplin, A. Iversen, I. Kühn, A. Manero, H. D. Taylor, and X. Vilanova. 2003. Comparison of enterococcal populations related to urban and hospital wastewater in various climatic and geographic European regions. J. Appl. Microbiol. 94:994-1002.

5. Choi, S., W. Chu, J. Brown, S. J. Becker, V. J. Harwood, and S. C. Jiang. 2003. Application of enterococci antibiotic resistance patterns for contamination source identification at Huntington Beach, California. Mar. Pollut. Bull. 46:748-755.

6. Coque, T. M., J. M. Steckelberg, J. E. Patterson, and B. E. Murray. 1995. Incidence of hemolysin, gelatinase and aggregation substance among enterococci isolated from patients with endocarditis, other infections and from 
feces of hospitalized and community based persons. J. Infect. Dis. 171:12231229 .

7. Dias Miguel, J. 2003. Poluiçao águas perigosas. Visão 2003:112-114.

8. Dukta-Malen, S., S. Evers, and P. Courvalin. 1995. Detection of glycopeptide resistance genotypes and identification to the species level of clinically relevant enterococci by PCR. J. Clin. Microbiol. 33:24-27.

9. Eaton, T. J., and M. J. Gasson. 2001. Molecular screening of Enterococcus virulence determinants and potential for genetic exchange between food and medical isolates. Appl. Environ. Microbiol. 67:1628-1635.

10. Gilmore, M. S., P. S. Coburn, S. R. Nallapareddy, and B. E. Murray. 2002 Enterococcal virulence, p. 301-354. In M. S. Gilmore (ed.), The enterococci: pathogenesis, molecular biology, and antibiotic resistance. American Society for Microbiology, Washington, D.C.

11. Guardabassi, L., and A. Dalsgaard. 2004. Occurrence, structure, and mobility of Tn1546-like elements in environmental isolates of vancomycin-resistant enterococci. Appl. Environ. Microbiol. 70:984-990.

12. Harwood, V. J., M. Brownell, W. Perusek, and J. E. Whitlock. 2001. Vancomycin-resistant Enterococcus spp. isolated from wastewater and chicken feces in the United States. Appl. Environ. Microbiol. 67:4930-4933.

13. Homan, W. L. D., S. Tribe, M. Poznanski, G. Li, E. Hogg, J. D. A. Spalburg R. L. J. van Embden, and Willems. 2002. Multilocus sequence typing scheme for Enterococcus faecium. J. Clin. Microbiol. 40:1963-1971.

14. Iversen, A., I. Kühn, M. Rahman, A. Franklin, L. G. Burman, B. OlssonLiljequist, E. Torell, and R. Möllby. 2004. Evidence for transmission between humans and the environment of a nosocomial strain of Enterococcus faecium. Environ. Microbiol. 6:55-59.

15. Iversen, A., I. Kühn, A. Franklin, and R. Möllby. 2002. High prevalence of vancomycin-resistant enterococci in Swedish sewage. Appl. Environ. Microbiol. 68:2838-2842

16. Kaufmann, M. E. 1998. Pulsed-field gel electrophoresis, p. 17-31. In N Woodford and A. P. Johnson (ed.), Methods in molecular medicine, vol. 15 Humana Press Inc., Totowa, N.J.

17. Lim, J. A., A. R. Kwon, S. K. Kim, Y. Chong, K. Lee, and E. C. Choi. 2002 Prevalence of resistance to macrolide, lincosamide and streptogramin antibiotics in gram-positive cocci isolated in a Korean hospital. J. Antimicrob. Chemother. 49:489-495.

18. National Committee for Clinical Laboratory Standards. 2000. Methods for dilution antimicrobial susceptibility tests for bacteria that grow aerobically. Approved standard M7-A5. National Committee for Clinical Laboratory Standards. Wayne, Pa.

19. Novais, C., T. M. Coque, J. C. Sousa, F. Baquero, and L. Peixe. 2004. Loca genetic patterns within a vancomycin-resistant Enterococcus faecalis clone isolated in three hospitals in Portugal. Antimicrob. Agents Chemother. 48: 3613-3617.

20. Soltani, M., D. Beighton, J. Howard, and N. Woodford. 2000. Mechanisms of resistance to quinupristin-dalfopristin among isolates of Enterococcus faecium from animals, raw meat, and hospital patients in Western Europe. Antimicrob. Agents Chemother. 44:433-436.

21. Tenover, F. C., R. D. Arbeit, R. V. Goering, P. A. Mickelsen, B. E. Murray, D. H. Persing, and B. Swaminathan. 1995. Interpreting chromosomal DNA restriction patterns produced by pulsed-field gel electrophoresis: criteria for bacterial strain typing. J. Clin. Microbiol. 33:2233-2239.

22. Tomita, H., C. Pierson, S. K. Lim, D. B. Clewell, and Y. Ike. 2002. Possible connection between a widely disseminated conjugative gentamicin resistance (pMG1-like) plasmid and the emergence of vancomycin resistance in Enterococcus faecium. J. Clin. Microbiol. 40:3326-3333.

23. Vakulenko, S. B., S. M. Donabedian, A. M. Voskresenskiy, M. J. Zervos, S. A. Lerner, and J. W. Chow. 2003. Multiplex PCR for detection of aminoglycoside resistance genes in enterococci. Antimicrob. Agents Chemother. 47: 1423-1426.

24. Vankerckhoven, V., T. Van Autgaerden, C. Vael, C. Lammens, S. Chapelle, R. Rossi, D. Jabes, and H. Goossens. 2004. Development of a multiplex PCR for the detection of asa1, gelE, cylA, esp, and hyl genes in enterococci and survey for virulence determinants among European hospital isolates of Enterococcus faecium. J. Clin. Microbiol. 42:4473-4479.

25. Vilanova, X., A. Manero, M. Cerda-Cuellar, and A. R. Blanch. 2004. The composition and persistence of faecal coliforms and enterococcal populations in sewage treatment plants. J. Appl. Microbiol. 96:279-288.

26. Whitman, R. L., D. A. Shively, H. Pawlik, M. B. Nevers, and M. N. Byappanahalli. 2003. Occurrence of Escherichia coli and enterococci in Cladophora (Chlorophyta) in nearshore water and beach sand of Lake Michigan. Appl. Environ. Microbiol. 69:4714-4719.

27. Willems, R. J. L., J. Top, N. van der Braak, A. van Belkum, D. J. Mevius, G. Hendriks, M. van Santen-Verheuvel, and J. D. van Embden. 1999. Molecular diversity of Tn1546-like elements in enterococci from humans and animals. Antimicrob. Agents Chemother. 43:483-491.

28. Wilson, I. G., and G. G. McAfee. 2002. Vancomycin-resistant enterococci in shellfish, unchlorinated waters, and chicken. Int. J. Food Microbiol. 79:143151.

29. Woodford, N., A. M. A. Adebiyi, M. F. I. Palepou, and B. Cookson. 1998 Diversity of VanA glycopeptide resistance elements in enterococci from humans and animals. Antimicrob. Agents Chemother. 42:502-508. 